\title{
Femtosecond laser-assisted arcuate keratotomy in correction of corneal astigmatism
}

\author{
Authors \\ *Corresponding Author \\ Mahmoud A. Sultan
}

Mahmoud A. Sultan ${ }^{1 *}$, Hazem E. Abdulghany ${ }^{2}$, Mansour H. Ahmed ${ }^{3}$

${ }^{1}$ Assistant lecturer, Dept. of Ophthalmology, Faculty of medicine, Beni-Suef University, Beni-Suef, Egypt.

${ }^{2}$ Associate Professor, Dept. of Ophthalmology, Faculty of medicine, Beni-Suef University, Beni-Suef, Egypt

${ }^{3}$ Professor, Dept. of Ophthalmology, Faculty of medicine, Beni-Suef University, Beni-Suef, Egypt.

\begin{abstract}
Background: Astigmatism is a major challenge for surgeons. Many measures have been studied to manage astigmatism starting from simple measures such as; contact Lenses, Spectacles. femtosecond LASER-assisted incisions decrease the risk of infection and associated pain. The arcuate relaxing incision (Arcuate keratotomy) provides a fast visual rehabilitation, economic, easy, and a relatively safe procedure for the management of astigmatism.

Subjects and Methods: This prospective study included 40 eyes of patients with different degrees of astigmatism. None of the patients had a history of previous ocular surgery or diseases that would affect the corneal refraction.

Incisions will be done at 65\% to 75\% depth, and arc lengths of 60 to 90.

Results: The mean Preoperative BCVA (LogMAR) was 0.56 improved to 0.35. The mean BCVA change (Postoperative - Preoperative) (LogMAR) showed an improvement of 0.21 (LogMAR) "gain of two lines". The mean Preoperative topographic astigmatism was 4.28 improved to 0.78. The mean Preoperative refractive astigmatism was 3.73 Diopter improved to0.88.

Conclusion and Recommendations: $A K$ is a simple and safe technique to manage astigmatism which involves the creation of relaxing incisions in the corneal stroma. AK have considerable technical limitations, including difficulty in the creation of uniform incisions and a lack of reproducibility and predictability. Recent rise in popularity of the femtosecond laser has led to its application in a variety of corneal procedures. It has proven to be a safe, effective and highly accurate instrument and continues to be studied for other operations because of its ability to produce precise incisions.
\end{abstract}

\section{Introduction}

Astigmatism is a major challenge for surgeons. Many measures have been studied to manage astigmatism starting from simple measures such as; contact Lenses, Spectacles.

Femtosecond LASER-assisted incisions for treating astigmatism is one of recent and favorable methods, the advantage here is preserving the epithelium, and this decreases the risk of infection and associated pain. Arcuate Incisions. The arcuate relaxing incision (Arcuate keratotomy) provides a fast visual rehabilitation, economic, easy, and a relatively safe procedure for the management of astigmatism. It is defined as 
creating one or more arc shaped incision in the cornea, it can be constructed using the blade, arcuate Keratome or Femtolaser. Moreover; it can be combined with Excimer LASER, stress sutures, and during cataract surgery.

\section{Principle}

Its main principle is flattening of the steep meridian, and that will also steepen the opposite unincised meridian that is 90 degrees away, which is known as the coupling ratio, the coupling ratio can be 1; where the flattening of the steep meridian and the steepening of the opposite meridian is equal and that will not change the spherical equivalent, However if the coupling ratio is more than one; that will result in more flattening of the incised meridian than the steepening of the un-incised opposite meridian leading to more flattening of the cornea and the spherical equivalent will be a hyperopic shift. And vice versa for the coupling ratio that are less than one; that will result in more steepening effect of the incised meridian than the effect of the unincised opposite meridian and it will result in a myopic shift of the spherical equivalent.

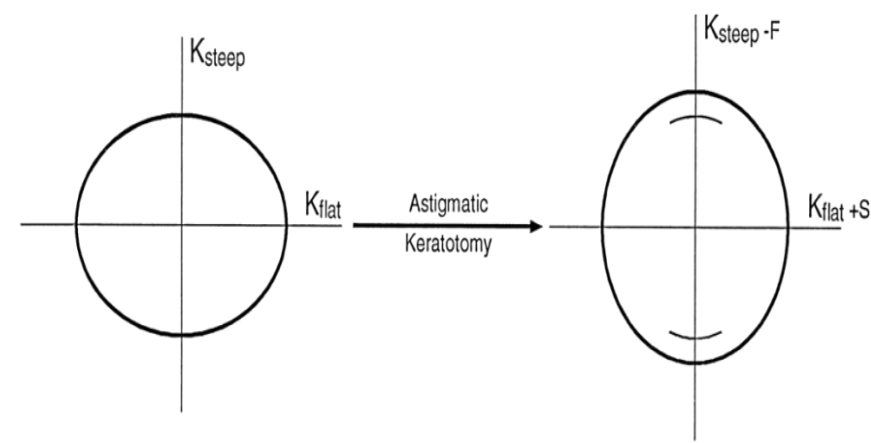

Figure 1: Change in the curvature of the principal Figurecorneal meridians induced by arcuate keratotomy.

$S_{\text {teep }}$ is the power of the steep preoperative meridian. $\mathrm{K}_{\mathrm{flat}}$ is the power of the flat preoperative meridian. After astigmatic keratotomy, the power of the incised meridian is $\mathrm{K}_{\text {steep }}-\mathrm{F}$, where $\mathrm{F}$ is flattening of the incised meridian. The power of the opposite, unincised meridian is $\mathrm{K}$ flat $+\mathrm{S}$, where $\mathrm{S}$ is steepening of the unincised meridian.

This is based on Gauss' Law, which states that: "For every change in curvature in one meridian there is an equal and opposite change 90 degrees away." It is often demonstrated by squeezing a balloon that will result in steepening one meridian and flattening the opposite other.

However, another law applies to the living cornea after an incision, "the law of the modified living elastic dome" (the law of the incised cornea) is as follows: "The change in curvature 90 degrees away from a corneal incision is proportional to the change in the primary meridian reduced by the increase in circumference.

Adding tissues to a dome flattens the dome due to the increase in its radius of curvature and ultimately decrease its refractive power, and vice versa. Corneal incisions act like adding tissue hence it will result in increasing the radius of curvature.

\section{Material and Method}

This study is a prospective and retrospective cohort study. We analyzed 40 consecutive eyes of patients intervened. Forty consecutive eyes fulfilled the inclusion criteria were obtained from November 2016 to December 2017.

Purpose: To study arcuate incisions outcome made by femtosecond laser in the management of astigmatism.

Design: Interventional case series.

Methods: This study will comprise 40 eyes that had an arcuate incision for correction of astigmatism. Informed consent obtained from all the patients enrolled.

\section{Inclusion Criteria}

$>$ Patient were adults (more than 18 years old).

$>$ Patients were of any sex.

$>$ None of the patients had a history of previous ocular surgery or diseases that would affect the corneal refraction.

\section{Exclusion Criteria}

$>$ High, irregular astigmatism that prevented proper estimation of the refraction and improvement of visual acuity.

$>$ Dry eye, untreated lid margin disease.

$>$ History of previous corneal surgery or diseases. 
$>$ Any active infectious disease or history of herpetic disease in the eye.

$>$ Visually Significant Cataract.

$>$ Pregnancy.

$>$ Collagen disease.

\section{Informed Consent}

The patients signed consent for intervention, including advantages and disadvantages, risks of possible complications and periodical follow-up.

\section{Preoperative Evaluation}

Data collection included demographic information, and corneal topography using Oculus Pentacam ${ }^{\circledR}$. All the patients were completely examined preoperatively including:

$>$ Refraction

$>$ Measurement of the best-corrected visual acuities (BCVA).

$>$ Slit-lamp examination.

$>$ IOP assessment.

$>$ Fundus examination.

$>$ Corneal topography, using the Oculus Pentacam ${ }^{\circledR}$.

\section{Operative Procedure}

All patients with astigmatism were offered an arcuate relaxing incision, the 6 O'clock position is marked while the patient is upright and looking straight ahead with both eyes open to avoid cyclotorsion, all eyes had at least 2 relaxing incision using a Femtosecond laser assisted keratotomy incisions done at $65 \%$ to $75 \%$ depth, and arc lengths of 60 to 90 degree arc of the thinnest point at the steepest hemi-meridian guided by the corneal topography, after surgery, topical antibiotic and steroids were prescribed. An example of pre-operative and post-operative pentacams are shown in figure 3,4 .

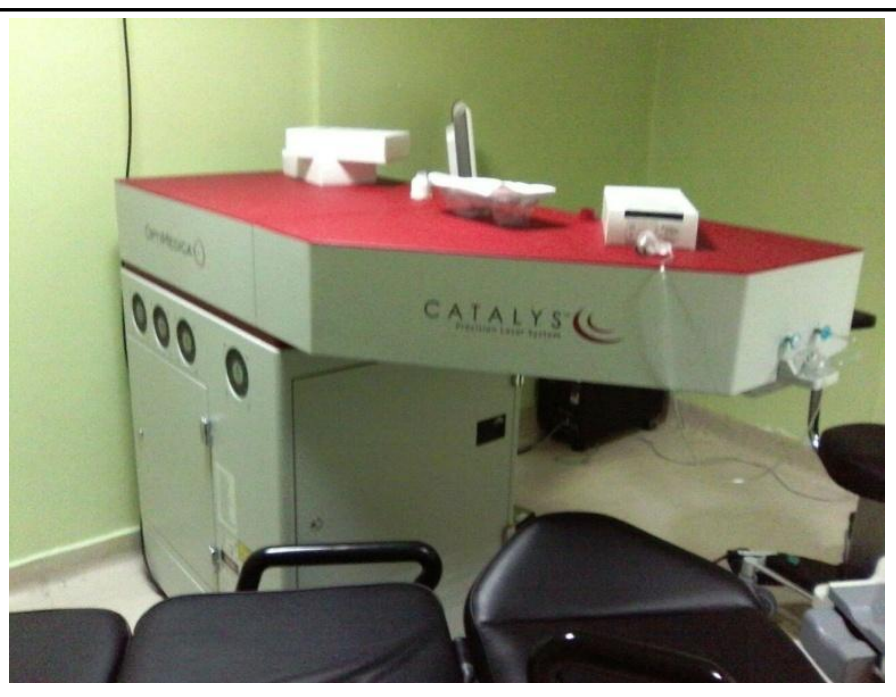

Figure 2: Catalys femtosecond laser

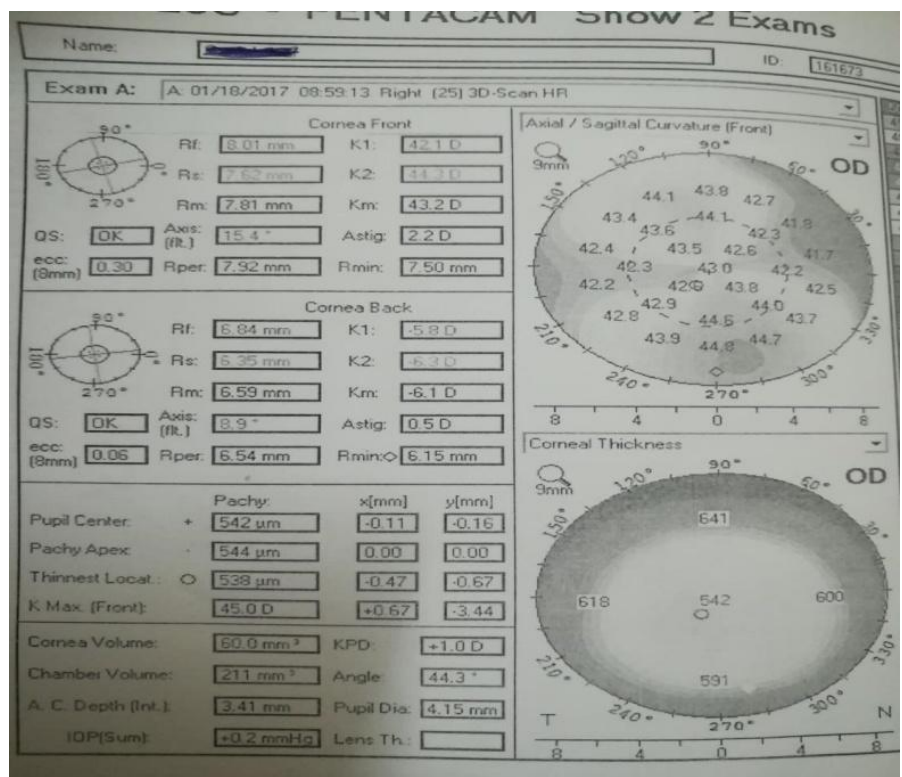

Figure 3 A pre-operative pentacam photo showing corneal astigmatism

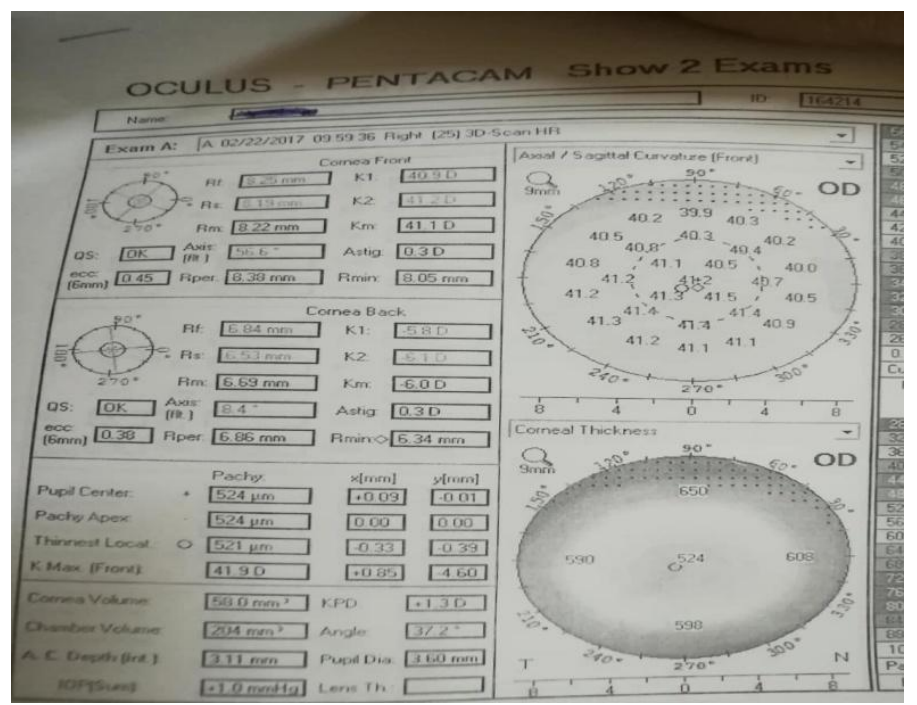

Figure 4 A post-operative pentacam photo showing improving of the astigmatism. 


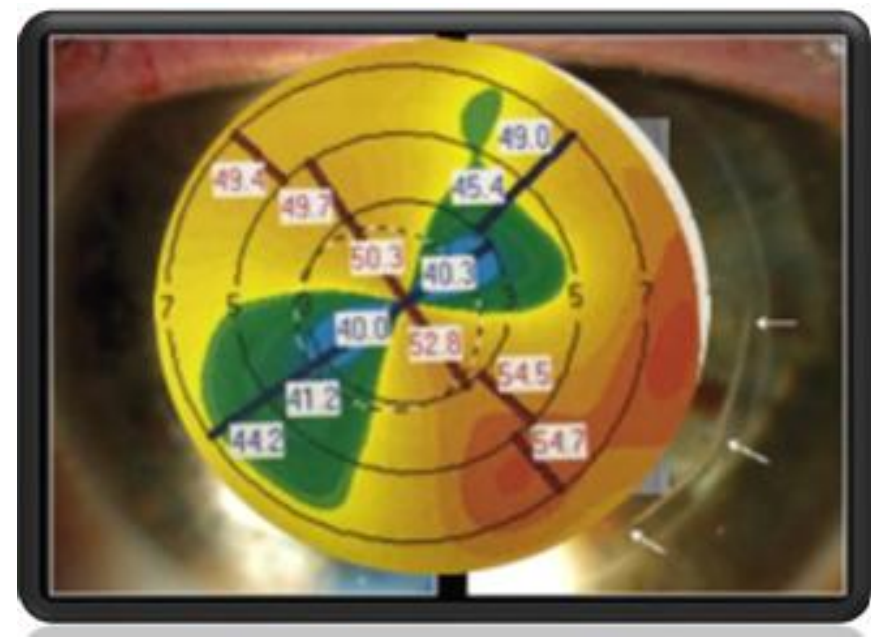

Figure 5 Arcuate incision at the steep meridian "A demonstration photo".

\section{Postoperative Follow Up}

Postoperative follow up examinations were performed on the first day post operatively, at week 1, at months 1, 2, 3 and Included:

$>$ Refraction.

Measurement of the best-corrected visual acuities (BCVA).

$>$ Slit-lamp examination.

$>$ IOP assessment.

$>$ Fundus examination.

$>$ Corneal topography, using the Oculus Pentacam ${ }^{\circledR}$.

$>$ The vector analysis was calculated using the Alpins method for vector analysis.

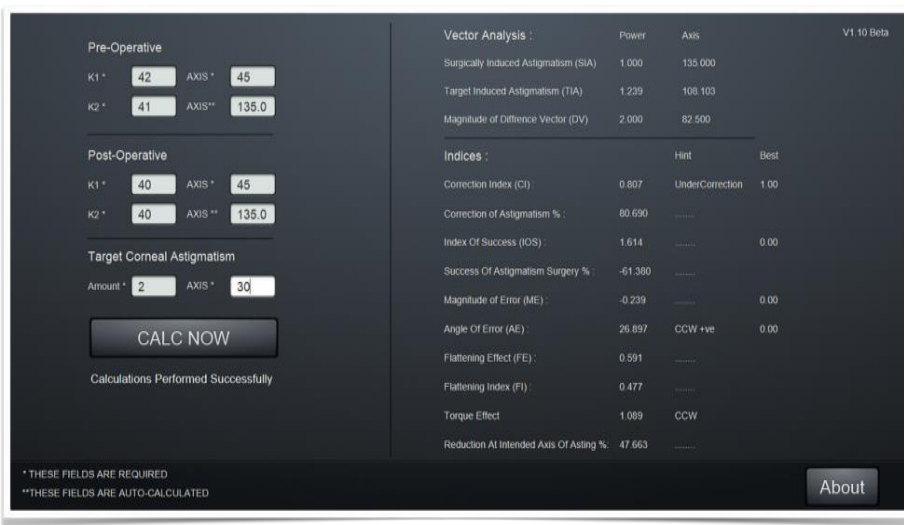

Figure 6: Our own software for astigmatic analysis.

\section{Statistical Analysis}

At the end of this study, data were statistically described in terms of mean \pm standard deviation
$( \pm$ SD), median, correlation and percentages when appropriate. All statistical calculations were made using computer programs IBM $®$ SPSS $®$ Statistics Version 22.

P-values less than 0.05 were considered significant.

\section{Results}

\section{Best Corrected Visual Acuity (LogMAR)}

In LogMAR, Each letter has a score value of 0.02 $\log$ units. Since there are 5 letters per line, the total score for a line on the LogMAR chart represents a change of $0.1 \mathrm{log}$ units.

The mean Preoperative BCVA (LogMAR) was 0.56 improved to 0.35 .

The mean BCVA change (PostoperativePreoperative) (LogMAR) showed an improvement of 0.21 (LogMAR) "gain of two lines". The results were statistically significant ( $\mathrm{p}$-value = $0.03)$.

\section{Topographic Astigmatism}

The topographic astigmatism was calculated using Pentacam (Oculus Inc., Lynnwood, Washington, USA) in the preoperative and postoperative visits.

Since we are mainly treating corneal astigmatism so this is the most accurate index of the effect of the surgery as it directly measures the effect of the treatment in the cornea.

The mean Preoperative topographic astigmatism was 4.28 improved to 0.78 .

The mean topographic astigmatism change (Postoperative- Preoperative) showed an improvement of 3.5. The results were statistically significant ( $\mathrm{p}$-value $=0.01)$.

\section{Refractive Astigmatism}

The mean Preoperative refractive astigmatism was 3.73 Diopter improved to 0.88 .

The mean refractive astigmatism change (Postoperative- Preoperative) showed an improvement of 2.85. The results were statistically significant ( $\mathrm{p}$-value $=0.03$ )

\section{Spherical Equivalent}

The mean spherical equivalent was -2.08 Diopters (D) changed to -0.08 . 
The mean spherical equivalent change (Postoperative - Preoperative) showed a change of -2.00 Diopters. The results were statistically significant $(p$-value $=0.02)$.

\section{Discussion}

\section{Improvement in the Visual Acuity}

Our Study showed an improvement of 0.22 (LogMAR) "gain of two lines". The Results were statistically significant ( $\mathrm{p}$-value $=0.03$ ).

Loriaut et al. studied the arcuate incision using the Femtosecond laser in 20 patients and their results showed an improvement in vision from 0.5 to 0.3 ( $\mathrm{p}$-value $=0.49)$.

Improvement in the Topographic Astigmatism The mean topographic astigmatism change showed an improvement of 3.5. The results were statistically significant ( $\mathrm{p}$-value $=0.01$ ).

The mean Preoperative topographic astigmatism was 4.28 improved to $0.78(81.77 \%)$.

In Loriaut et al. Femtosecond laser study, the mean topographic astigmatism decreased from $(9.45 \mathrm{D})$ to $(4.64 \mathrm{D})(\mathrm{P}=0.001)$, they showed a $50 \%$ improvement, which was below our study and almost the same as Kubaloglu et al. study.

\section{Improvement in the Refractive Astigmatism}

In our study, the mean Preoperative refractive astigmatism was 3.73 Diopter improved to 0.88 .

In our study, the mean refractive astigmatism change (Postoperative - Preoperative) showed an improvement of 2.85 (76.4\%). The results were statistically significant ( $p$-value $=0.03$ ).

In Loriaut et al. Femtosecond laser study, The mean Preoperative refractive astigmatism decreased by 3.79 D. However, they didn't report the mean Preoperative astigmatism.

\section{Improvement in the Spherical equivalent}

In our study, the mean spherical equivalent was 2.08 Diopter changed to -0.08 .

In our study, the mean spherical equivalent change (Postoperative - Preoperative) showed a change of -2.00 Diopter. The results were statistically significant $(\mathrm{p}$-value $=0.02)$.
However, In Kubaloglu et al. Study although they didn't calculate the change, but their results show a hyperopic shift so that their coupling ratio was more than one.

In Loriaut et al. 2015 Femtosecond laser study, The mean spherical equivalent was $-4.34 \mathrm{D}$ changed to $-4.44 \mathrm{D}$, showing a myopic shif.

\section{Conclusion}

The assessment of the surgical treatment of astigmatism using the Alpins method is considered an accurate and effective method for the proper evaluation of astigmatism, as it deals with astigmatism not just in the dioptric power of the cylinder, but it also takes the cylinder axis into consideration, hence it deals with astigmatism as a vector, then using the mathematical or graphical vectors summations, besides Alpins Indices, it can show the effectiveness of the surgical treatment.

Moreover the editorial staffs of the Journal of Refractive Surgery, the Journal of Cataract and Refractive Surgery and the cornea journal have proposed a standard for reporting astigmatism for any astigmatism published study and they acknowledged the Alpins method for a better and a more detailed reporting of astigmatism; especially in incisional surgery just like our study. The arcuate relaxing incision is considered an effective and safe procedure in reducing the astigmatism and improving the best corrected visual acuity. In our study; there was a mild overcorrection, and mild rotation of treatment (Torque).

Mechanical incisions made leading to a) variation in achieving the actual $90 \%$ depth we sought b) variation in the verticality of the incisions (ie: not always possible to know that the incisions were placed perfectly perpendicular to the surface of the cornea c) Variation of the length of incisions variable

A Moorefields study showed that the higher the astigmatism, the greater the effect of the same number and length of relaxing incisions. A Relative low number of cases for analysis, and with this much variability, it is difficult to draw conclusions. 


\section{References}

1. Akura J, Matsuura K, Hatta S, Otsuka K, Kaneda S, 2001. Clinical application of full-arc, depth-dependent, astigmatic keratotomy. Cornea, 20(8), pp.839-843.

2. Alpins, N., 2001. Astigmatism analysis by the Alpins method. Journal of Cataract and Refractive Surgery, 27(1), pp.31-49.

3. Alpins, N.A., 1993. A new method of analyzing vectors for changes in astigmatism. Journal of cataract and refractive surgery, 19(4), pp.524-533.

4. Alpins, N.A., 1997. Vector analysis of astigmatism changes by flattening, steepening, and torque. Journal of cataract and refractive surgery, 23(10), pp.15031514.

5. Anwar, M. \&Teichmann, K.D., 2002. Journal of Cataract and Refractive Surgery, 28(3), pp.398-403.

6. Buzard, K., Febbraro, J.-L. \& Fundingsland, B.R., 2004. Laser in situ keratomileusis for the correction of residual ametropia after penetrating keratoplasty. Journal of cataract and refractive surgery, 30(5), pp.1006-13.

7. Cecil, R L F, L Goldman, and A I Schafer. 2012. Goldman's Cecil Medicine,Expert Consult Premium Edition -- Enhanced Online Features and Print, Single Volume,24: Goldman's Cecil Medicine. CECIL TEXTBOOK OF MEDICINE. Elsevier/Saunders.

https://books.google.com.eg/books?id=QdvvNh0ee0C.

8. Coscarelli S, Ferrara G, Alfonso JF, Ferrara P, Merayo-Lloves J, Araújo LP, Machado AP, Lyra JM, Torquetti L, 2012. Intrastromal corneal ring segment implantation to correct astigmatism. Journal of cataract and refractive surgery, 38(6), pp.1006-13.

9. De la Paz MF, Sibila GR, Montenegro G, de Toledo JA, Michael R, Barraquer R, Barraquer J, 2010. Wedge resection for high astigmatism: refractive and histopathologic changes. Cornea, 29(6), pp.595-600.

10. Dierick, H., 2001. The cornea is not a piece of plastic. Journal of refractive surgery (Thorofare, N.J.: 1995), 17(1), p.76; author reply 77-8.

11. Dua, Harminder S., Lana A. Faraj, Dalia G. Said, Trevor Gray, and James Lowe. 2013. "Human Corneal Anatomy Redefined." Ophthalmology 120 (9): 1778-85. doi:10.1016/j.ophtha.2013.01.018.

12. Dursun, D., Forster, R.K. \&Feuer, W.J., 2003. Surgical technique for control of myopia, astigmatism, and anisometropia. American Journal of Ophthalmology, 135(6), pp.807-815.

13. El-Danasoury, A., 2013. International ophthalmology clinics, 53(1), pp.41-53.

14. Faktorovich, E.G., Maloney, R.K. \& Price, F.W., 1999. Effect of astigmatic keratotomy on spherical equivalent: results of the Astigmatism Reduction Clinical Trial. American journal of ophthalmology, 127(3), pp.260-9.

15. Fares, A A Mokashi,M S Elalfy, and H S Dua, 2013. Eye (London, England), (May), pp.1-6.

16. Forseto, A.D.S., Marques, J.C. \& Nosé, W., 2010. Photorefractive keratectomy with mitomycin C. Cornea, 29(10), pp.1103-8.

17. Gallagher, Betty, and David Maurice. 1977. "Striations of Light Scattering in the Corneal Stroma." Journal of Ultrasructure Research $61 \quad$ (1): 100-114. doi:10.1016/S0022-5320(77)90009-0.

18. Hanna KD, Hayward JM, Hagen KB, Simon G, Parel JM, 1993. Keratotomy for astigmatism using an arcuate keratome. Archives of ophthalmology, 111(7), pp.998-1004.

19. He, Jiucheng, Nicolas G Bazan, and Haydee E P Bazan. 2010. "Mapping the Entire Human Corneal Nerve Architecture.” Experimental Eye Research 
91

(4):

513-23.

doi:10.1016/j.exer.2010.07.007.

20. Hjortdal, J.O. \& Ehlers, N., 1998. Paired arcuate keratotomy for congenital astigmatism. Acta Ophthalmologica Scandinavica, 76(2), pp.138-141.

21. Hogan, M J, J A Alvarado, and J E Weddell. 1971. Histology of the Human Eye: An Atlas and Textbook [by] Michael J. Hogan, Jorge A. Alvarado [and] Joan Esperson Weddell. Saunders. https://books.google.com.eg/books?id=29J qAAAAMAAJ.

22. Holland, S., 2014. Topography-Guided Photorefractive Keratectomy for Irregular Astigmatism. In The Annual ASCRS and ASOA Symposium and Congress. Ascrs.

23. Hope-Ross MW, McDonnell PJ, Corridan PG, Naylor G, Tan-Yee A, 1993. Eye (London, England), 7 ( Pt 5), pp.625-8.

24. Imamoglu S, Kaya V, Oral D, Perente I, Basarir B, Yilmaz OF, 2014. Corneal wavefrontguided customized laser in situ keratomileusis. Journal of cataract and refractive surgery, 40(5), pp.785-92.

25. Javadi MA, Motlagh BF, Jafarinasab MR, Rabbanikhah Z, Anissian A, Souri H, Yazdani S., 2005. Cornea, 24(8), pp.9416.

26. Koffler, B.H. \& Smith, V.M., 1996. Corneal topography, arcuate keratotomy for astigmatism. Journal of refractive surgery (Thorofare, N.J. : 1995), 12(2), pp.S306-S309.

27. Kubaloglu A, Coskun E, Sari ES, Guneş AS, Cinar Y, Piñero DP, KutluturkI, Ozerturk Y, 2011. Effect of astigmatic keratotomy in high astigmatism. American journal of ophthalmology, 151(4), pp.637643.e1.

28. Kymionis GD, Yoo SH, Ide T, Culbertson WW, 2009. Femtosecond-assisted astigmatic keratotomy for irregular astigmatism. Journal of Cataract and Refractive Surgery, 35, pp.11-13.
29. Lindquist TD, Rubenstein JB, Rice SW, Williams PA, Lindstrom RL, 1986. Trapezoidal astigmatic keratotomy. Quantification in human cadaver eyes. Archives of ophthalmology, 104(10), pp.1534-9.

30. Lipshitz, I., Loewenstein, A. \& Lazar, M., Astigmatic keratotomy followed by photorefractive keratectomy in the treatment of compound myopic astigmatism. Journal of refractive and corneal surgery, 10(2Suppl), pp.S282-4.

31. Loriaut, P., Borderie, V.M. \& Laroche, L., 2015. Femtosecond-Assisted Arcuate Keratotomy

32. for the Correction of Astigmatism : Vector Analysis and Accuracy of Laser Incisions. Cornea, 34(9), pp.1063-1066.

33. Morris E, Kirwan JF, Sujatha S, Rostron CK, 1998. Eye (London, England), 12 ( $\mathrm{Pt}$ 4)(0), pp.619-22.

34. Poll JT, Wang L, Koch DD, Weikert MP, 2011. Correction of astigmatism during cataract surgery: toric intraocular lens compared to peripheral corneal relaxing incisions. Journal of refractive surgery (Thorofare, N.J. : 1995), 27(3), pp.165-71.

35. Price FW, Grene RB, Marks RG, Gonzales JS, 1995. Astigmatism reduction clinical trial: a multicenter prospective evaluation of the predictability of arcuate keratotomy. Evaluation of surgical nomogram predictability. ARC-T Study Group. Archives of ophthalmology, 113(3), pp.277-82.

36. Reinstein, D.Z., Archer, T.J. \& Randleman, J.B., 2014. JRS Standard for Reporting Astigmatism Outcomes of Refractive Surgery. Journal of Refractive Surgery, 30(10), pp.654- 659.

37. Riddle, H.K., Parker, D.A.S. \& Price, F.W., 1998. Management of astigmatism. Current Opinion in Ophthalmology, 9(4), pp.15-28. Roper-Hall, M.J., 1991. Ophthalmology, 98(5), p.561. Sarhan, 
A.R.S. et al., 2010. Eye (London, England), 24(4), pp.540-6.

38. Smolin, G, C S Foster, D T Azar, and C H Dohlman. 2005. Smolin and Thoft'sThe Cornea: Scientific Foundations and Clinical Practice. Lippincott Williams \& Wilkins.

https://books.google.com.eg/books?id=93s 6aes5ob0C.

39. SZENTMÁRY, BERTHOLD SEITZ, FEBO, ACHIM LANGENBUCHER, GOTTFRIED O.H. and NAUMANN, 2005. correction of high or irregular astigmatism. American Journal of Ophthalmology, 139(5), pp.826-830.

40. Tahzib, N.G., Cheng, Y.Y.Y. \&Nuijts, R.M.M.A., 2006. Three-Year Follow-up Analysis of Artisan Toric Lens Implantation for Correction of Ametropia in Phakic and Pseudophakic Eyes. Ophthalmology, 113(6), pp.976-984.

41. Terry, M. a, 2000. The evolution of lamellar grafting techniques over twentyfive years. Cornea, 19(5), pp.611-6.

42. Thoft, R A, and J Friend. 1983. "The X, Y, $\mathrm{Z}$ Hypothesis of Corneal Epithelial Maintenance." Investigative Ophthalmology \& Visual Science 24 (10): 1442-43.

http://www.ncbi.nlm.nih.gov/pubmed/661 8809.

43. Thornton, S.P., 1990. Astigmatic keratotomy: A review of basic concepts with case reports. Journal of Cataract \& Refractive Surgery, 16(4), pp.430-435.

44. TRIPATHI, RAMESH C., and BRENDA J. TRIPATHI. 1984. "Chapter 1 Anatomy of the Human Eye, Orbit, and Adnexa." In The Eye, 1-268. doi:10.1016/B978-0-12-206901-7.50006-

3 .
45. Van Meter WS, Gussler JR, Soloman KD, Wood TO, 1991. Astigmatism Control. Ophthalmology, 98(2), pp.177-183.

46. Viestenz A, Küchle M, Seitz B, Langenbucher A, 2005. Toric intraocular lenses for correction of persistent corneal astigmatism . Der Ophthalmologe : Zeitschrift der Deutschen Ophthalmologischen Gesellschaft, 102(2), pp.148-152.

47. Wetterstrand, O., Holopainen, J.M. \&Krootila, K., 2013. Treatment of astigmatism using femtosecond laserassisted intrastromal relaxing incisions. Journal of refractive surgery (Thorofare, N.J. : 1995), 29(6), pp.378-82.

48. Wilkins, M.R., Mehta, J.S. \& Larkin, D.F.P., 2005. Journal of cataract and refractive surgery, 31(2), pp.297-301.

49. Zirm, E.K., 1989. Refractive \& corneal surgery, 5(4), pp.258-61.

50. Zuberbuhler B, Agrawal A, Gale R, Kipioti T, Gauba V, Noble B, 2007. Modified Ruiz procedure for reducing high astigmatism. Cornea, 26(10), pp.1171-7. 